\title{
Why Only Focus on One Variety of English? A Problem in EIL Teaching in Vietnam
}

\author{
Hang Thi Nhu Mai \\ Quang Binh University, Vietnam \\ e-mail: hangmainhu88qb@gmail.com
}

\begin{abstract}
Although research has proposed the urgent need of exposing learners to World Englishes for enhancing learners' intercultural competence, Standard English, which is either British English or American English, still remains dominant in English language classrooms in the Vietnamese context. This qualitative-designed case study aims to explore Vietnamese higher-education teachers' explanations for the reasons behind and their perspectives towards embracing World Englishes in English language classrooms. The study employed semi-structured interviews to collect data from five Vietnamese lecturers. The participants' answers were recorded before being converted into an Excel sheet. A Coding Process of Inductive Analysis (Cresswell, 2002) was adapted to analyze data. The results indicated that the factors including fixed materials, limited classroom time, teachers' previous training in Standard English (SE) for their degrees, and learners' favor of SE accounted for the main use of Standard English in language classrooms. Interestingly, however, all of the participants agreed that increasing knowledge of World Englishes is substantially necessary for successful intercultural communications. Moreover, learners are supposed to keep their identity in international encounters through their own English accents while still ensuring mutual intelligibility. The study drew on an implication for teachers to take an active role as transformative intellectuals in classrooms to make the EFL teaching process meet Vietnamese learners' goals and needs.
\end{abstract}

Keywords: Standard English, World Englishes, Vietnamese teachers' perspectives, qualitative study 


\section{INTRODUCTION}

English with its new functions and roles nowadays has been regarded as the most dominant international language of the twenty-first century, which is used in various domains including international trade, entertainment, education, and global communications (British Council, 2013). Graddol (2006) puts it down to the globalization process that contributes to the growing number of international companies and their operations in different parts of the globe, leading to workers increasingly having to communicate with colleagues in other countries. Furthermore, the development of technologies and information network enables people around the world to quickly connect with one another with just a click (Kramsch, 2014). Linguistic scholars have argued that the global demands for English learning do not likely come from people looking for opportunities to immigrate into Englishspeaking countries but from individuals who need to be able to communicate in multilingual and multicultural contexts. English is in fact a common communication tool among interlocutors from around the world.

Due to that trend, English has been enriched in different ways as a result of a contact with other languages by its various users (Hamid and Baudauf, 2013). It is obvious that people can greatly benefit from this development of the language; however, it also poses a range of challenges to English language teaching and learning in many polities. As Dennett (1992) asserts, "English may be the language of the global village, but the villagers are far from agreement on what is the good use of language" (p. 13). In fact, there exists a controversial debate about what should be taught in the language classrooms. Proponents of Standard English maintain that American English or British English should be mainly focused in schools because that is the 'perfect' English. However, opponents argue that using English spoken by speakers in the Inner Circle as the target language of instruction across contexts may be somehow inappropriate to meet the local context and learners' needs in the international community. It is said that Standard English provides the common language principles that are crucial for the global intelligibility while World Englishes might be very helpful for intercultural encounters.

Despite these debates, the dominant approaches to English language teaching in Vietnam tend to conceptualize English as a static language of the mother tongue speakers, which refers the native's language as the target model (Hoang, 2011; Le, 2011). This paper argues that teachers should not focus on only one variety of English and ignore the others, that is, not only insist on Standard English but also make learners aware of other varieties of English around the world.

\section{LITERATURE REVIEW}

\subsection{Standard English verse World Englishes}

First of all, Standard English (SE) is used to refer to the English language spoken by the speakers in the Inner Circle countries presented by Kachru (1985). McArthur (2003) proposes that Standard English is taken to be "the variety most widely accepted, understood, and perhaps valued within an English-speaking country" (p. 442). Although it is still difficult to identify what is 'standard', linguists share the following consensus, including (1) SE is most easily identified in print, (2) 
SE is used by most newscasters on the media such as radio and television networks, and (3) its usage relates to social class and education level.

Along with the spread of English as a global language, different varieties of English have been arisen. As such, there is a need to use a new concept to refer to these varieties; that is, World Englishes. According to Kachru (1992), the terms 'Englishes' is used to refer to "the functional and formal variations, divergent sociolinguistic contents, ranges, and varieties of English in creativity, and various types of acculturation in parts of the Western and non- Western world" (p. 2). Bolton (2004) points out three interpretations of World Englishes. Firstly, World Englishes serves as "an umbrella" label covering all varieties of English in the world. Secondly, it is used to refer to the so-called New Englishes in Africa, Asia, and the Caribbean. Thirdly, it represents the pluricentric approach to the study of English.

Kachru (1985) categories the usage of English into three concentric circles. The first so- called Inner Circle refers to the language spoken in the UK, the US, Canada, Australia and New Zealand. The second so-called Outer Circle includes the countries that experienced the extended periods of colonization, essentially by the users of the inner circle varieties, such as Nigeria, Singapore, India. The last circle called Expanding Circle includes people who use English for business, education, and other international purposes, such as China, Indonesia, Japan, Vietnam, and so on. Nowadays the number of non-native speakers significantly overcomes that of native speakers. Regarding the large population of English speakers in the world, Kachru (1985) suggests that English has "a unique cultural pluralism, and a linguistic heterogeneity and diversity" (p. 14).

\subsection{Literature on Problems of a Single Variety of English in English language classrooms}

\subsubsection{Negative Aspects of Standard English}

Proponents of Standard English as an international model have missed the important point that English in the twenty-first century is no longer the language of the UK or the US or any single country and single group of speakers, but it is a global language. As such, the variety of the language is essential. Therefore, merely focusing on Standard English and considering it as the criterion for assessing learners' language proficiency seems to cause some controversial issues.

In the first place, Standard English is a native-speaker model which is unachievable to second language (L2) learners (McKay, 2000). As Bloomfield (1933) asserts, "the first language a human being learns to speak is his native language, he is a native speaker of this language" (p. 43). That is to say, to become a native speaker of a language, an individual must learn from childhood. Cook (1999), hence, argues that it is unrealistic to second language learners to attain a nativespeaker model while they cannot "become native-speakers without being reborn" (p. 187). In addition, Widdowson (1994) proposes that Standard English is not simply a communication tool; it involves the native's conventions, cultural norms, and values. In the EFL context, learners neither have opportunities to be exposed to the target language nor communicate with people in the native English-speaking environment. It poses a controversial question that why second language learners need to acquire 
all values of the native speakers while they live and use the language in a very different context.

Furthermore, insisting on only Standard English appears to restrict learners' language creativity and ignore the variation and the development of English as a global language. It is observed that when Standard English is the only requirement in schools, World Englishes are commonly considered a deficient type of English (Seidlhofer, 2001), which in fact cannot promote the creativity of language use from L2 learners to some extent. As Kachru (1985) maintains, "the native speakers of this language seem to have lost the exclusive prerogative to control its standardization. What we need now are new paradigms and perspectives for linguistic creativity in multilingual situations across cultures" (p. 30). In particular, 'linguistic creativity' refers to the creation of a localized linguistic identity of variety (e.g., Indian English, Scottish English, Singlish) which is called nativisation (Kachru, 1992). A paradigm example of the bilingual creativity is the development of contact literature in World Englishes. Such contact literature result from the contact of English with other languages in multilingual and multicultural contexts in Africa and Asia. The contact varieties are showed in their "pronunciation, syntax, vocabulary, and style strategies" (Kachru, 1992, p. 6). It would be problematic to devalue the dialects or sociolects created by the language contact and consider them inferior or failed to meet the qualities of Standard English. It is because many features of L2 English are natural innovations in language contact situations (Leitner, as cited in Hamid \& Baldauf, 2013), as such they should be treated equally as the language of the Inner Circle countries.

\subsubsection{Negative Aspects of World Englishes}

In the era of globalization, the number of non-native English speakers using English as a common communication tool surpasses that of native speakers. Some advocates of World Englishes, therefore, argue that they should be taught in schools because that is what learners need to successfully communicate in an international community. It might be true to some extent; however, focus on teaching World Englishes also draws out some concerns.

First of all, World Englishes might not have international intelligibility. As Hung (2002) asserts, mutual intelligibility is not only pronunciation but also regards to "lexical, grammatical, discoursal, and cultural matter" (p. 6). Smith and Nelson (1985) identify three basic levels of intelligibility, including (1) word recognition, (2) utterance comprehension, (3) and understanding the meaning behind the utterance. Smith (1992) maintains that many varieties of English are not mutually intelligibility. In this sense, Deterding and Kirkpatrick (2006) conducted a study to investigate features of pronunciation that cause break-down communication among teachers from ten countries of the Associations of South East Asian Nations (ASEAN). Data were collected by recording conversations among twenty EFL teachers who were participating a course at the SEAMEO Regional Language Centre (RELC) in Singapore. The finding demonstrated some different examples of pronunciation among people from different countries that were factors of misunderstanding in their communication. In particular, there was the use of [a:] in 
pearl and having a [ $\mathrm{t}$ ] in us by Malaysian teachers, omitting the $/ \mathrm{r} /$ in three and the use of [n] at the end of holes by Lao teachers, pronouncing sauce with an initial [J] by Vietnamese teachers. The communication problems arose since none of those mentioned above features of pronunciation were shared by speakers from other ASEAN countries. All of these five features are the ones that Jenkins (2000) found generate problems in international communication (p. 406). The above evidence reinforces Melchers and Shaw's claim that although intelligibility may not be a problem at a local level, it can be problematic on a global basis.

Similarly, Farell and Kun (2007) carried out a classroom observation to investigate the use of Singlish in three Singapore Elementary classrooms. The finding revealed some distinct features in Singlish, which were not found in any other varieties of English, for example, the absence of past tense marking (e.g., what happen yesterday?), 'be' deletion (e.g., he playing), the use of "got" as "there is" (e.g, got a playground lah), the absence of subject-verb agreement (e.g., he do not know), and the use of borrowings (e.g., $N$ always kacau her). The authors emphasized that although these features of English could be learned without difficulties by the Singaporean learners, they might encounter difficulties in communication with other English speakers outside Singapore. Given that reason, in a recent concerted effort to prevent the use of Singlish in classrooms, the Singapore government embarked 'The Speak Good English Movement' (SGEM) in 2000 with the aim of promoting the use of 'good' English among Singaporeans (p. 381).

Above all, the literature reveals a range of disadvantages of focusing on one variety of English in EFL classrooms. However, the motive for teaching practice might depend on many contextual factors including institutional syllabus, teachers' beliefs, and local learners' needs and goals. This empirical research aims to explore the reasons behind the dominance of Standard English in language classrooms in the Vietnamese context according to higher-education teachers' views and their perspectives towards exposing learners to World Englishes in English classrooms. The research questions are as follows:

1. What are the reasons for the dominance of Standard English in language classrooms in the Vietnamese context according to teachers' views?

2. What are Vietnamese tertiary teachers' perspectives towards exposing learners to World Englishes in English classrooms?

\section{RESEARCH METHOD}

\subsection{Participants}

The participants in the study were five lecturers of English at Quang Binh University and Hue College of Foreign Languages in Vietnam. Two of the participants from Quang Binh University were the researchers' colleagues while the other three were invited through emails which listed on their institution' website. The participants included four females and one males who were in between 30 to 45 years old. All of them were junior and senior teachers of English, with over eightyear teaching experience. 


\subsection{Semi-structured interview}

Two of the participants from Quang Binh university were interviewed in person while other three teachers from Hue college were interviewed online through skype. Before the interview, interviewing questions were checked with two other colleges who were teaching English at Quang Binh University for a pilot test. Based on comments from the participants, some improvements for the questions have been made, such as facilitating the meaning of some complex questions, changing question structures and reordering the questions to make it more logical.

All of the interviews were recorded and were named with five pseudonyms for later analysis.

\subsection{Data analysis}

The study employed an inductive approach, which involves using the actual data to obtain the structure of analysis, to analyze qualitative data. It is a comprehensive approach which is the most suitable where little or nothing is known about the study phenomenon (Burnard, Stewart, Treasure, \& Chadwick, 2008). This approach is the most common for qualitative data analysis, thereby the focus of this study.

Table 1 below illustrated an overview of the coding process of the study. The intended outcome of the process was to create at least three and a maximum of five summary categories. These categories were the most important ones given the research objectives.

Table 1: The Coding Process in Inductive Analysis

\begin{tabular}{|l|l|l|l|l|}
\hline $\begin{array}{l}\text { Initial read } \\
\text { through text } \\
\text { data }\end{array}$ & $\begin{array}{l}\text { Identify } \\
\text { specific } \\
\text { segments of } \\
\text { information }\end{array}$ & $\begin{array}{l}\text { Label the } \\
\text { segments of } \\
\text { information to } \\
\text { create categories }\end{array}$ & $\begin{array}{l}\text { Reduce overlap } \\
\text { and redundancy } \\
\text { among the } \\
\text { categories }\end{array}$ & $\begin{array}{l}\text { Create a model } \\
\text { incorporating } \\
\text { most important } \\
\text { categories }\end{array}$ \\
\hline $\begin{array}{l}\text { Many pages } \\
\text { of text }\end{array}$ & $\begin{array}{l}\text { Many } \\
\text { segments of } \\
\text { text }\end{array}$ & $\begin{array}{l}15-20 \\
\text { categories }\end{array}$ & $\begin{array}{l}7-10 \\
\text { categories }\end{array}$ & $3-5$ categories \\
\hline
\end{tabular}

Note. Adapted from Educational research: Planning, conducting, and evaluating quantitative and qualitative research (p. 244), by J. Cresswell, 2002, Upper Saddle River, NJ: Merrill Prentice Hall. Copyright 2002 by Pearson Education, Inc.

Member-checking. The analysed data were sent to the participants through email for their feedback as to whether the interpretation reflected exactly their responses.

\section{FINDINGS AND DISCUSSION}

Research Question 1: What are the reasons for the dominance of Standard English in language classrooms in the Vietnamese context according to teachers' views?

All of five teachers shared the same answer for American English and British 
English when being asked about which English varieties they used in English classrooms. The overwhelming reason among the participants was pertaining to the fixed materials in the school which were designed and written in Standard English by authors from English-speaking countries, preventing teachers from exposing learners to other varieties of English. Furthermore, teachers were trained in Standard English for their degrees, leading to teachers' lack of confidence to introduce other varieties of English such as Singlish or Indian English to learners. Also, all of the interviewees coincidentally highlighted learners' preference to American English or British English, which forces them to acquire a standard accent. Two participants stated as follows,

P3: I will feel very ashamed when my learners think that my accent sounds like Vietnamese English rather than American English. And in fact there is a comparison of teachers among learners regarding to standard accent.

P5: I want to let my students know about some vocabulary and other accents of English besides Standard English. However, I have to follow the school syllabus which sets a target goal to help learners achieve standardized language and fixes the chosen classroom materials.

Most of them (four out of five interviewees) expressed their powerlessness before the institutional principles, which substantially accounted for their passiveness in their teaching practice.

However, all of them also agreed that common rules of grammar and pronunciation in Standard English helped to facilitate mutual understanding. They shared a consensus that Standard English assisted learners in reaching a global intelligibility rather than just local intelligibility.

\section{Research Question 2: What are Vietnamese tertiary teachers' perspectives towards exposing learners to World Englishes in English classrooms?}

Three of the interviewers had a consensus that learners need to be exposed to various accents of English to be well-prepared for international communications. They explained that learners might encounter various accents and voices spoken by speakers from multi-nations. Also, they claimed that to understand other people, learners need to be acquainted with vocabulary and cultural contexts of the communication. Therefore, cultivating knowledge of other variants of English is, by no means, greatly advantageous for learners. One interviewee said,

P1: I think that teaching one or two English varieties, such as British English or American English, is not adequate for learners to successfully communicate in international encounters. As Vietnamese learners seem to have more opportunities to work and interact with different first-language speakers, they need to understand their colleagues rather than only Westerners. For example, if you are working in an Indian company, it's better if you know some Indian English so that you can understand what your boss says. Added with that, Indian accents are quite different and not easy to follow. If you are not familiar with their pronunciations, then you might misunderstand their talk. 
In addition, most of the respondents said that exposure to varieties of English could make learners aware of the variation of English today so that they can determine the best way to master the language to suit its changing socio-linguistic reality.

Two of the respondents also noted that the development of the Internet enhanced the cross-cultural communication; and the spread of information network in the global era allowed learners to have quick access to various resources and topics in whatever varieties of English. The other interviewees added that learners would be able to address international communication problems better if they were well-prepared for those situations with the knowledge of different English varieties in the world.

However, most of the participants (four out of five teachers) also expressed their concerns regarding limited classroom time and their lack of experience in other varieties of English, which might prevent them from putting all of their ideas on World Englishes into practice. Therefore, it is crucial for teachers to introduce learners with the development and the new roles of English as an international language so that they can learn about World English outside classroom to meet their needs.

Regarding to whether learners should develop Vietnamese English, all of the respondents showed an indifferent opinion. The teachers emphasized that they encourage students to use English with common standards or try to speak as close to the native as possible to ensure global intelligibility. Nevertheless, in the assessment of language proficiency, the native model should not be used as a criterion but mutual intelligibility.

\section{DISCUSSION AND IMPLICATIONS}

The findings indicated teachers' feeling of powerlessness in the face of institutional and curricular prescriptions. In other words, teachers have no choice for which variety of the language to teach since it will be assigned by the government or the school directors. However, it is suggested that teachers should not be that of 'passive technicians', they could be 'transformative intellectuals' in practice. To be more precise, teachers can make learners cognizant of the existing variations of English in the world. At the same time, teachers should explain the nature of the language variation and its significance (Hamid \& Baldauf, 2013). It means that although some aspects of Standard English such as grammar rules and pronunciation will be taught in the classroom, learners are still provided opportunities to know about other varieties and can decide to explore them more outside the classroom for their real life needs. For example, teachers can provide resources of English varieties on the Internet, radio, television and newspapers from around the world (Cook 1999). On the Internet, teachers can provide samples of many national and regional varieties of English through the International Corpus of English site (www.ucl.ac.uk/english-usage/ ice), or World-Newspapers (www.worldnewspapers.com). Some English language television channels are also provided on the Internet, such as New Delhi Television (www.ndtv.com) in which Indian English is spoken (Farrell and Martin, 2009). In addition, teachers should provide learners 
with the opportunity to talk about the sociocultural norms of their own cultures "so that sociocultural convergence can be negotiated within the ad hoc speech community" (El-Sayed, as cited in Farrell \& Martin, 2009, p. 5). For example, Vietnamese learners could be given opportunities to explain why they do not use the word 'please' in many situations in the Vietnamese culture. As Jenkins (2006) states, making learners aware of their cultural differences will help to minimize misunderstandings since it will foster greater tolerance in communication. In Vietname, Huyen \& Phan (2013) believe that the teachers have been exposed to English as an international language (EIL), which should offer space for alternative frameworks within which learners and teachers could view each other differently.

In addition, teachers should act like gatekeepers to correct learners' errors on one hand; however, on the other hand, they should be aware of innovations of the language to nurture learners' linguistic creativity. Research has shown that it is hard to distinguish between errors and variants. Nevertheless, it does not mean that teachers should ignore varietal features of the language and negate its benefits in making the language adjust a particular communication context. As such, it is believed that L2 practitioners are supposed to "apply the notion of intelligibility as a criterion to judge L2 use which has been advocated by scholars" (Hamid \& Baldauf, 2013 , p. 489). Some opponents might argue that local intelligibility might be a problem of global intelligibility; however, grammar and pronunciation are not the only aspects of the language. It also includes some other aspects such as L2 users' cultures, which in fact can make the language more understandable and acceptable. Teachers should also notice learners that a particular language can be used in this context but might not be accepted in other contexts so that they are aware of selecting the appropriate language in a specific setting.

\section{CONCLUSION}

In conclusion, the study revealed that American and British English are the two dominant variety used by educators due to some contextual factors including the fixed syllabuses and materials, teachers' previous training in Standard English, learners' favor of Standard English, and limited classroom time. However, teachers also realized that exposing learners to only Standard English was not adequate for learner's needs and goals in the era of globalization when English is considered as an international language. All of them contended that learners should be taught common rules of grammar and standard pronunciation for global intelligibility; nevertheless, learners are to be aware of different varieties of English, so-called World Englishes. By that way, learners cultivate their knowledge about the target language, and, hence, can formulate appropriate learning strategies to meet the new demands of society.

\section{References}

Bloomfield, L. (1933). Language. New York: Holt Rinehart Winston. Bolton, K. (2004). World englishes. In A. Davies \& C. Elder (Eds.), The handbook of applied linguistics (pp. 369-396). Oxford, England: Blackwell. 
British Council. (2013). The English effect. Retrieved from https://www.britishcouncil.org/sites/default/files/english-effect-report-v2.pdf

Burnard, P., Gill, P., Stewart, K., Treasure, E., \& Chadwick, B. (2008). Analysing and presenting qualitative data. British Dental Journal, 204, 429-432. doi:10.1038/sj.bdj.2008.292

Cook, V. (1999). Going beyond the native speaker in language teaching. TESOL Quarterly, 33, 185-209.

Creswell, J. W. (2002). Educational research: Planning, conducting, and evaluating quantitative and qualitative research . Upper Saddle River, NJ: Pearson Education.

Dennett, J. T. (1992). World language status does not ensure world class usage. IEEE Transactions on Professional Communication, 35(1), 13.

Derterding, D., \& Kirkpatrik, A. (2006). Emerging south!east asian englishes and intelligibility. World Englishes, 25(3!4), 391-409. doi:10.1111/j.1467971X.2006.00478.x

Farrell, T. S. C., \& Kun, S. T. K. (2007). Language policy, language teachers' beliefs, and classroom practices. Applied Linguistics, 29(3), 381-403. doi:10.1093/applin/amm050

Graddol, D. (2006). English next. London, England: British Council. Retrieved from http://www.britishcouncil.org/learning-research-english-next.pdf

Hamid, M. O., \& Baldauf, R. B. (2013). Second language errors and features of world englishes. World Englishes, 32(4), 476-494. doi:10.1111/weng.12056

Hoang, V. V. (2011). The current situation and issues of the teaching of English in Vietnam. International Symposium on The Teaching of English in Asia, 2, 718.

Hung, T. T. N. (2002). English as a global language and the issue of international intelligibility. Asian Englishes, 5(1), 4-17. doi:10.1080/13488678.2002.10801086

Huyen, L. T. T., \& Phan, H. L. (2013). Problematizing the culture of learning English in Vietnam: Revisiting teacher identity. In Martin Cortazzi \& Lixian Jin (Ed.), Researching cultures of learning, (pp. 248-264). New York: Palgrave Macmillan.

Jenkins, J. (2000). The phonology of english as an international language. Oxford: Oxford University Press.

Jenkins, J. (2006). Current perspectives on teaching world englishes and english as a lingua franca. TESOL Quarterly, 40(1), 157-181.

Farrell, T. S., \& Martin, S. (2009). To teach standard english or world englishes? A balanced approach to instruction. English Teaching Forum, 47(2), 2-7.

Kachru, B. B. (1985). Standards, codification and sociolinguistic realism: The english language in the outer circle. In R. Quirk \& H. G. Widdowson (Eds.), English in the world: Teaching and learning the language and literatures (pp. 11-30). Cambridge, England: Cambridge University Press.

Kachru, B. B. (1992). World englishes: Approaches, issues and resources. Language Teaching, 25(1), 1-14. doi:10.1017/S0261444800006583

Kramsch, C. (2014). Teaching Foreign Languages in an Era of Globalization: 
Introduction. The Modern Language Journal, 98(1), 2014.

Le, S. T. (2011). Teaching English in Vietnam: Improving the provision in the private sector Doctoral dissertation, Vicroria University). Retreived from http://vuir.vu.edu.au/id/eprint/16055

McArthur, T. (2003). The oxford guide to world english. Oxford: Oxford University Press.

McKay, S. L. (2000). Teaching english as an international language: Implications for cultural materials in the classroom. TESOL journal, 9(4), 7-11. doi:10.1002/j.19493533.2000.tb00276.x

Seidlhofer, B. (2001). Closing a conceptual gap: The case for a description of English as a lingua franca. International Journal of Applied Linguistics, 11, 133-158.

Smith, L. E. (1992). Spread of english and issues of intelligibility. In B. B. Kachru (Ed.), The mother tongue: english across cultures (pp. 75-90). Chicago: University of Illinois Press.

Smith, L. E., \& Nelson, C. L. (1985). International intelligibility of english: directions and resources. World Englishes, 4(2), 333-42.

Widdowson, H. G. (1994). The ownership of English. TESOL Quarterly, 28, 377389. 